\title{
Suspected retinopathies in Norwegian optometric practice with emphasis on patients with diabetes: a cross-sectional study Vibeke Sundling*1, Pål Gulbrandsen ${ }^{2}$, Ragnheiður Bragadottir ${ }^{3}$, Leiv S Bakketeig ${ }^{4}$, Jak Jervell ${ }^{5}$ and Jørund Straand ${ }^{6}$
}

\begin{abstract}
Address: ${ }^{1}$ Department of Optometry and Visual Science, Buskerud University College, Kongsberg, Norway, ${ }^{2}$ Helse Øst Health Services Research Centre, Akershus University Hospital and Faculty of Medicine, University of Oslo, Oslo, Norway, ${ }^{3}$ Department of Ophthalmology, Ullevål University Hospital Faculty Division Ullevål University Hospital, University of Oslo, Oslo, Norway, ${ }^{4}$ Division of Epidemiology, National Institute of Public Health, Oslo, Norway, ${ }^{5}$ Professor Emeritus, Bygdøy alle 25 A, 0262 Oslo, Norway and ${ }^{6}$ Department of General Practice and Community Medicine, University of Oslo, Oslo, Norway

Email: Vibeke Sundling* - vibeke.sundling@hibu.no; Pål Gulbrandsen - pal.gulbrandsen@ahus.no;

Ragnheiður Bragadottir - ragnheib@medisin.uio.no; Leiv S Bakketeig - leiv.bakketeig@fhi.no; Jak Jervell - j.a.jervell@klinmed.uio.no; Jørund Straand - Jorund.Straand@samfunnsmed.uio.no

* Corresponding author
\end{abstract}

Published: 8 February 2008

BMC Health Services Research 2008, 8:38 doi:10.1186/1472-6963-8-38

This article is available from: http://www.biomedcentral.com//472-6963/8/38

(C) 2008 Sundling et al; licensee BioMed Central Ltd.

This is an Open Access article distributed under the terms of the Creative Commons Attribution License (http://creativecommons.org/licenses/by/2.0), which permits unrestricted use, distribution, and reproduction in any medium, provided the original work is properly cited.
Received: 19 April 2007

Accepted: 8 February 2008

\begin{abstract}
Background: The scope of optometry differs worldwide. In Norway the vast majority of optometrists perform ophthalmoscopy as part of their routine examinations. The aim of this study was to describe the frequency of suspected retinopathies in patients seen for routine optometric examination and to determine how optometrists deal with these patients.

Methods: 212 optometrists participated in a questionnaire survey and a practice registration during November 2004 - May 2005. In the practice registration, details for 20 consecutive patient encounters were recorded. Data were analysed by chi-square tests and multiple logistic regression.

Results: All optometrist stated that ocular history taking was an integrated part of their routine examination, while general health and diabetes history were routinely addressed by $59 \%$ and $42 \%$ of the optometrists, respectively. During the practice registration 4,052 patient encounters were recorded. Ophthalmoscopy was performed in $88 \%$ of the patients, of which $2 \%$ were dilated fundus examinations. Retinopathy was suspected in 106 patients, of whom 3I did not report a previous history of ocular or systemic disease. Old age (75+), hypertension and diabetes strongly predicted retinopathy with odds ratio $(95 \% \mathrm{Cl})$ of $6.4(4.2$ to 9.9$), 3.8$ (2.4 to 6.0) and 2.5 (1.4 to 4.7), respectively. Diabetic retinopathy was seen in $10 \%$ of diabetic patients and suspected in $0.2 \%$ of patients with no established history of diabetes. Retinopathy was not confirmed in 9 out 18 patients with a history of diabetic retinopathy; seven of these had undergone laser treatment. Out of the 106 patients with findings of retinopathy, 28 were referred to an ophthalmologist or a general practitioner (GP), written reports were sent to a GP in 16 cases, ten patients were urged to contact their GP for further follow up, while 52 were considered in need of routine optometric follow up only.
\end{abstract}

Conclusion: Optometric practice provides a low threshold setting for detecting cases of ocular disease and retinal manifestations of systemic disease in the population. At present diagnosis of retinopathy in Norwegian optometric practice is unreliable. There are potentials for improving the optometrists' routine examination, their patient management patterns and collaboration routines with medical doctors. 


\section{Background}

The scope of optometry differs worldwide [1] and, more specifically, in Europe [2] ranging from dispensing of optical aids to the diagnosis and treatment of certain ocular diseases. In various countries, there is disparity in the legal recognition of optometry as a health care profession. Since 1988 Norwegian optometric practice has been regulated by The Health Personnel Act, which is founded on the principles of responsible conduct.

In the Scandinavian population, retinal disorders are the most common reason for visual impairment (66\%), and in the working age population, diabetes represents a leading cause (13\%) [3]. The reported prevalence of diabetic retinopathy differs widely [4]. Most people with diabetes will develop some degree of retinopathy, and 11-30\% will develop sight threatening retinopathy during the course of their illness [5-9].

Studies have shown optometrists are able to detect and grade diabetic retinopathy[10] and specially trained optometrist perform well when screening for diabetic retinopathy using dilated, indirect ophthalmoscopy [1113]. The vast majority of Norwegian optometrists perform ophthalmoscopy as part of their routine examinations
[14], and dilated fundus examination can be undertaken by optometrists certified to use ocular diagnostic drugs. Norwegian optometrists with specific certification were given the privilege to acquire and use ocular diagnostic drugs in 2004. At the time of the study $9 \%$ of Norwegian optometrists had this privilege, which requires approved education in the use of ocular diagnostic drugs.

There are few studies describing diagnosis and management of retinopathy in routine optometric practice. The aim of this study was to establish the prevalence of possible retinopathy in diabetic and non-diabetic individuals seen in routine optometric practice, to determine the proportion of previously unknown ocular and systemic disease and, finally, to explore how optometrists deal with such patients during everyday practice. The study did not assess or validate the optometrists' findings.

\section{Methods}

All members of the Norwegian Association of Optometrists (NAO) working in optometric practice in the community were invited to participate in a questionnaire survey. In addition, 29 practicing non-member optometrists who heard about the study volunteered to participate, making the total sample 790, figure 1. All

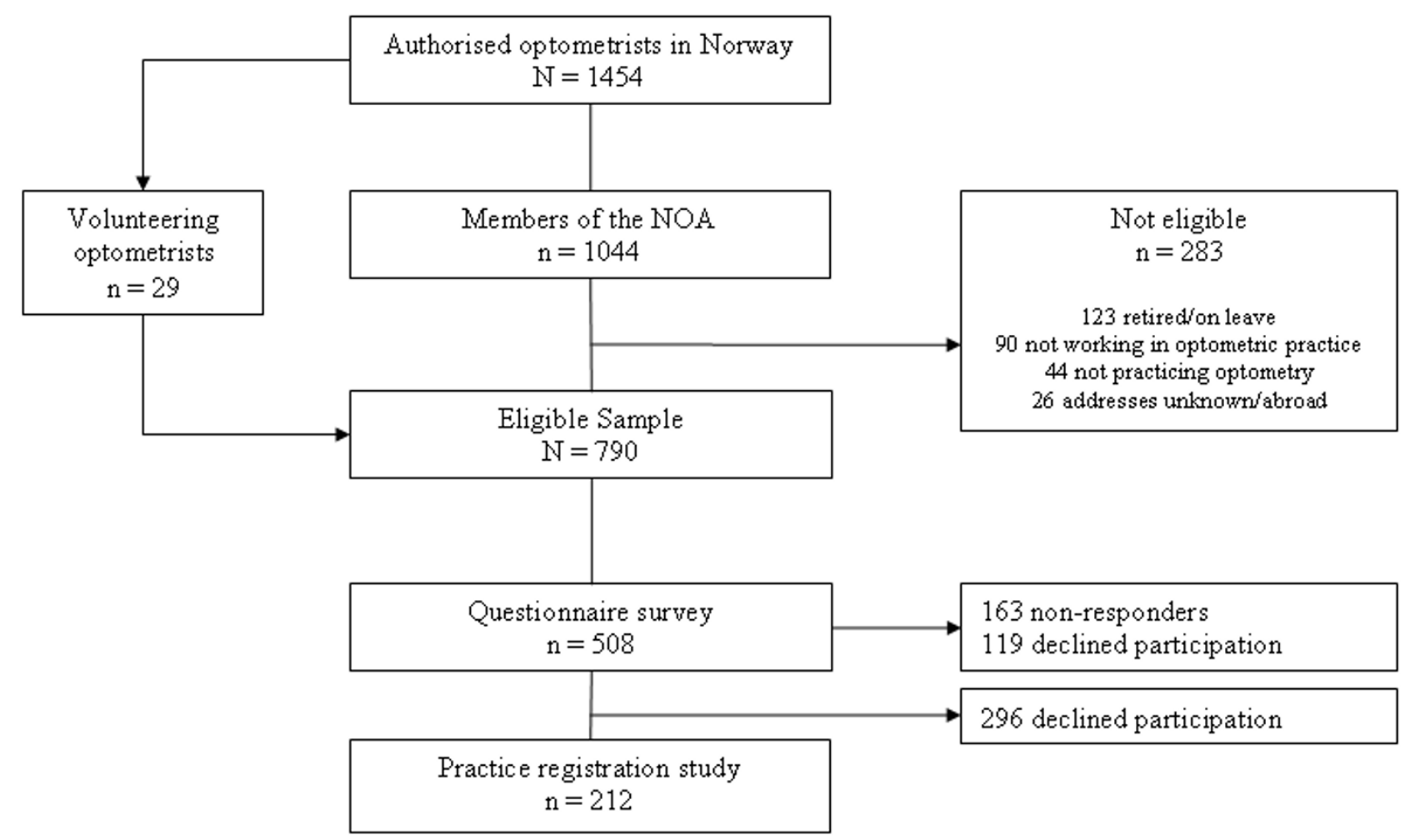

Figure I

Selection of optometrists in the study. 
questionnaire responders $(\mathrm{n}=508)$ were also asked to take part in a practice registration. During November 2004 - May 2005, 212 Norwegian optometrists participated in both the questionnaire survey and the practice registration. The survey has been described elsewhere [14].

In the questionnaire, the optometrists were asked about their education and work experience, practice habits (history taking and examination), opinions on important principles of practice and their collaboration with general practitioners (GPs) and ophthalmologists. In the practice registration, each optometrist recorded the following data for 20 consecutive patients seen for a full eye examination: demographics, patient's history, best corrected visual acuity, intra-ocular pressure, ocular diseases, and how the patients were dealt with (e.g. referral, written report to physicians). Data were reported by the optometrists on a registration form. Recorded ocular diseases were: patientreported history of cataract, glaucoma and/or age related macular degeneration (AMD) and suspected cataract and/ or suspected retinopathy. In Norway diagnosis of ocular disease is not in the scope of optometric practice and the terms suspected or possible retinopathy are used to reflect that these are tentative diagnosis as reported by the optometrists. Additionally patient reported history of: hypertension, cardiovascular disease and diabetes were recorded. In patients with history of diabetes were also asked about type of diabetes, illness duration, treatment, HbA1c-values, blood pressure, diabetic retinopathy, and laser treatment.

The study was presented to Regional Committee for Medical Research Ethics; the study was not regarded subject to specific evaluation and approval. The Norwegian Social Science Data Services were notified prior to commencement of the study. A notice was posted in the consulting room/practice notifying patients of the ongoing practice registration. Patient data was unidentified before it was passed on to the research team and the responding optometrists were anonymous to the researchers.

Differences between proportions were analysed using chisquare tests. Features associated with suspected retinopathy were analysed by univariate and multiple logistic regression. The statistical package SPSS version 12.0.2 was used.

\section{Results}

All optometrists reported that a history of vision and ocular health was part of their routine examination. Respectively, $59 \%$ and $42 \%$ of the optometrists also addressed general health and diabetes in the patient history taking for all patients. Ophthalmoscopy was part of the routine examination for the majority of optometrists $(96 \%)$. One out of four optometrists was qualified to perform dilated fundus examination. Direct ophthalmoscopy was most frequently used (60\%). One out of four reported slit lamp indirect ophthalmoscopy as the most frequent method and one out of ten used both direct and indirect ophthalmoscopy in most patients.

During the practice registration, 4,052 patient encounters were recorded, 2,216 (57\%) with females. The patients' age distribution is shown in figure 2. Among the patients, 166 had a known history of diabetes, 439 had known hypertension, while 125 had some other known cardiovascular disease (hypertension excluded). In patients with a history of diabetes, 34 reported a known history of hypertension and 14 reported a known history of other cardio-vascular disease (hypertension excluded).

Ophthalmoscopy was performed in 3,576 (88\%) of the patients, of which $78(2 \%)$ were dilated fundus examinations. In patients with known diabetes, ophthalmoscopy was performed significantly more often than in non-diabetics ( $96 \%$ vs $88 \%, \mathrm{p}=0.002)$. Tentative retinopathy was found in $106(3 \%)$ patients, of whom 57 (59\%) were females. Almost half of these patients were 75 years or older, and none were younger than 16 years. In patients with diabetes, $35 \%$ of the possible retinopathies were found in the age group 16-64 years. There were no statistically significant differences with regard to gender, age, and known history of hypertension and/or cardiovascular disease between diabetic and non-diabetic patients with findings of retinopathy.

The most common tentative diagnosis made during fundus examination was macular disease (Table 1). More than half of the patients had no previous history of AMD. Diabetic retinopathy was suspected in 23 patients, among whom six had no established history of diabetes and 14 had no previous history of retinopathy. In patients with suspected hypertensive/vascular retinopathy, 10 out of 27 had no history of hypertension and/or cardiovascular disease and none had a history of diabetes.

Multiple logistic regression analysis showed that old age $(75+)$, hypertension and diabetes were independent predictors of retinopathy (all kinds), with odds ratio (95\% CI) of 6.4 (4.2 to 9.9), 3.8 (2.4 to 6.0) and 2.5 (1.4 to 4.7), respectively. For vascular retinopathy only diabetes and hypertension were independent predictors with odds ratio $(95 \% \mathrm{CI})$ of 7.2 (3.7 to 14.1 ) and 4.9 (2.6 to 9.3), respectively.

Diabetic retinopathy was seen in $17(10 \%)$ of the diabetic patients, of these nine had reported history of diabetic retinopathy. However, retinopathy was not described by the optometrists in 9 out of 18 patients with reported his- 


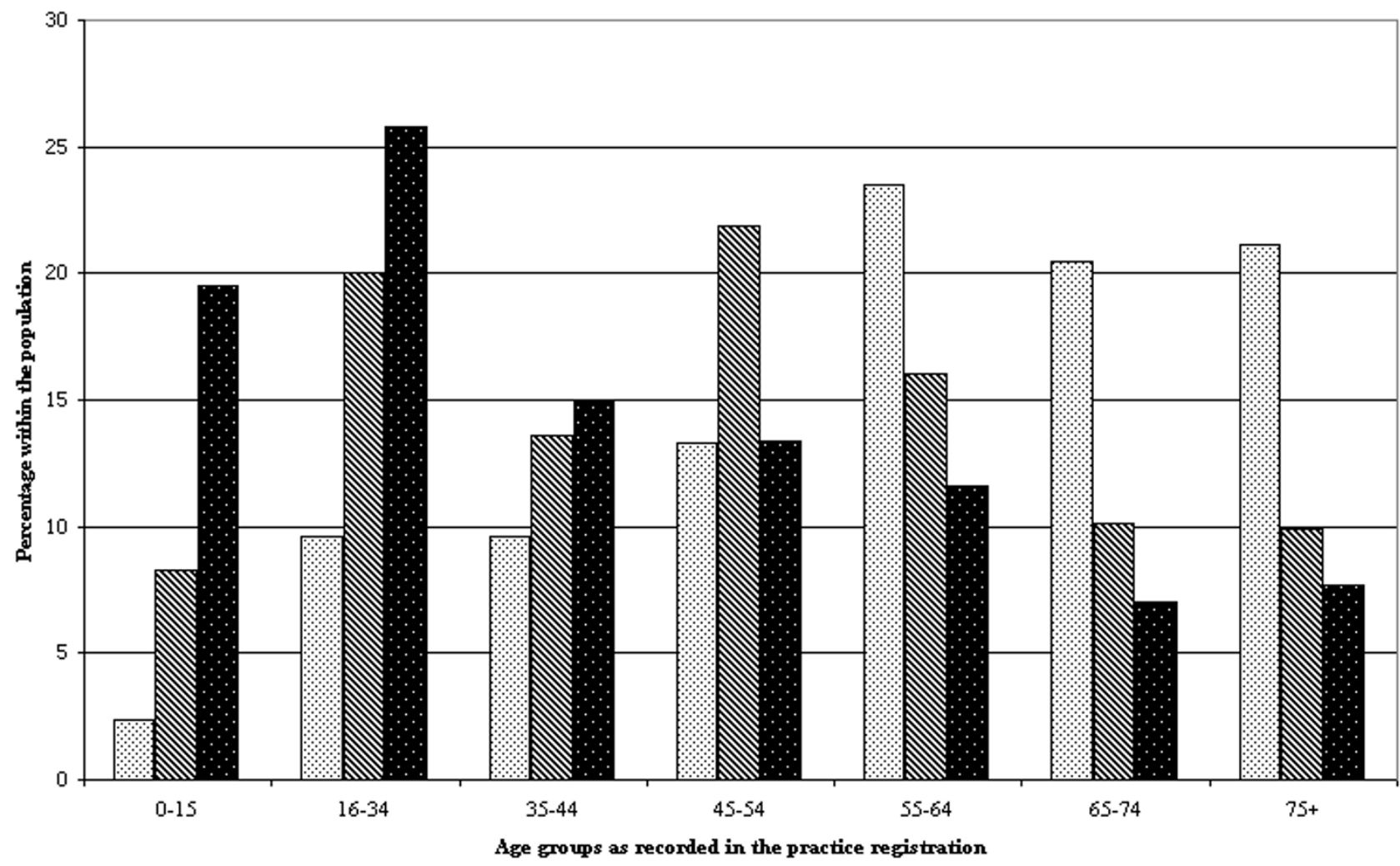

$\checkmark$ Diabetic patients seen in optometric practice $\mathbf{\Delta}$ Non-diabetic patients seen in optometric practice $\mathbf{T}$ The Nowegian general population

\section{Figure 2}

Age distribution of diabetic and non-diabetic patients seen in Norwegian optometric practice compared to the age distribution of the Norwegian population. $\square$ Diabetic patients seen in optometric practice, $\square$ Non-diabetic patients seen in optometric practice, The Norwegian population.

Table I: Clinical findings in 3,576 fundus examined encounters and management* by tentative diagnosis and history.

\begin{tabular}{|c|c|c|c|}
\hline $\begin{array}{l}\text { Optometrists' tentative diagnosis and } \\
\text { patients' history }\end{array}$ & $\mathbf{n}$ & $\begin{array}{l}\text { Referral/report/patient } \\
\text { urged to contact doctor }\end{array}$ & No/routine optometric follow up \\
\hline Diabetic retinopathy & 23 & 12 & II \\
\hline No history of retinopathy & 14 & 8 & 6 \\
\hline History of retinopathy & 9 & 4 & 5 \\
\hline Hypertensive/vascular retinopathy & 27 & 16 & II \\
\hline No history of retinopathy & 26 & 15 & II \\
\hline History of retinopathy & 1 & 1 & \\
\hline Macular disease ${ }^{\dagger}$ & 56 & 26 & 30 \\
\hline No history of retinopathy & 31 & 18 & 13 \\
\hline History of retinopathy & 25 & 8 & 17 \\
\hline All retinopathies & 106 & 54 & 52 \\
\hline No retinopathy & 3,470 & 385 & 3,085 \\
\hline
\end{tabular}

* Fisher's Exact Test $p<0.00$ I between patients with findings of retinopathy and patients with no findings of retinopathy

† Fisher's Exact Test $p=0.003$ between patients with retinopathy findings and known history of retinopathy and patients with retinopathy findings and no history of retinopathy. 
tory of diabetic retinopathy. Seven of these nine patients reported to have undergone laser treatment. There were no significant differences with regard to gender, age, type of diabetes, diabetes treatment, history of hypertension or cardiovascular disease between diabetic patients with findings of retinopathy $(\mathrm{n}=17)$ and diabetic patients with no retinopathy $(\mathrm{n}=147)$.

In total, 439 of the $3,576(12 \%)$ fundus examined patients were judged by the optometrists to be in need of some medical follow up (referral, report or patient consultation) of the ocular findings (Table 1).

Retinopathy was suspected in 3\% of the patients seen in optometric practice; of whom two thirds had no previous history of retinopathy. More than half of the suspected retinopathies were considered to be in need of some further management by a medical practitioner. Patients with retinopathy were more frequently prompted to contact a physician if the retinopathy was previously unknown (41/ 71 vs. $13 / 35, p=0.003)$. The reason for non-referral of patients with findings of retinopathies was not explored.

\section{Discussion}

In our study population, the proportion of vascular retinopathy seen in non-diabetics was lower than expected according to figures reported in epidemiological studies [15]. This could be due to the low frequency of dilated fundus examinations in our study. Dilated indirect ophthalmoscopy and photographic grading have a higher sensitivity than direct ophthalmoscopy in detection of retinal abnormalities $[16,17]$. The low frequency of dilated fundus examinations in our study can be explained by the small number of optometrist qualified to perform dilated ophthalmoscopy and the recent introduction of the privilege to acquire and use ocular diagnostic drugs.

Reported prevalence of diabetic retinopathy varies widely. In Scandinavia, prevalence between 13.8 and $75.1 \%$ have been reported in people with diabetes [4], this is higher than the proportion detected by Norwegian optometrists in their practice. However, we do not know how well diabetic patients seen in optometric practice correspond with the diabetic population in the community. The lower number of retinopathies among diabetics seen in optometric practice may reflect a selection bias; diabetic patients should have their retinas regularly examined by an ophthalmologist according to guidelines [18]. Diabetic patients with retinopathies may therefore be less likely to go to an optometrist.

Nine reported cases of retinopathy were not described by the optometrists; however, most of these patients had undergone laser treatment. A possible explanation may be that scarring from laser treatment has not been regarded as retinopathy by the optometrists. However, the retinopathies not detected by the optometrists and the overall low numbers of retinopathies observed among both nondiabetics and diabetics may also represent a poor diagnostic sensitivity. Unfortunately, our data did not permit us to validate the quality of the optometrists' diagnostic work.

The optometrists' follow-up decisions in patients with findings of retinopathy should raise some concern. Only one quarter of the patients with suspected vascular retinopathy and no known history of retinopathy or related systemic disease were only considered to be in need of optometric routine follow up. This practice is probably not acceptable. In general, these patients should be seen by a physician as retinal microvascular changes are related to long-term hypertension, type 2 diabetes, impaired glucose metabolism, obesity, dyslipidemia, stroke and an increased cardiovascular mortality [19]. This may suggest that optometrists make medical judgements and that patient management depends on their evaluation of the ocular findings, not solely on the patient's history. However, our numbers are low and the reason for non-referral has not been recorded in the study, the interpretation should therefore be considered with caution. If some optometrists do take inappropriate medical responsibility, one possible explanation could be inadequate report and referral routines and lack of established collaboration with medical practitioners.

Previous studies of optometrist's effectiveness in screening for diabetic retinopathy have revealed a specificity ranging from 62 to $95 \%$ and a sensitivity of 70 to $87 \%$ [11-13,17] Based on the reported prevalence of diabetic retinopathy in the Norwegian diabetic population (13.8\%) [20] and the number of retinopathies missed $(n=9)$ and detected $(\mathrm{n}=17)$ by the optometrists in this study, we propose that the diagnostic specificity must be high. It is unlikely that report/referral of cases of suspected retinopathy will impose undue pressure on the health care services. This is supported by a previous study by Riise et al [21] which concluded that $94 \%$ of referrals form Norwegian optometrists were clinically relevant. However, taking the low diagnostic sensitivity into consideration suggests that the routine examination as currently undertaken by Norwegian optometrists is an unreliable method of screening for diabetic retinopathy. Moreover, the study illustrates the disparity of optometric practice in Europe and worldwide with regard to training and the role in the health care system, emphasizing the importance that health policies decisions are founded on the practice in the community were the policy will be employed.

Some limitations of the study should be taken into consideration. First, as compared to the non-participants, the optometrists who took part in this study tended to be 
younger, more were females, and they had in general higher education and worked in smaller communities[14]. Hence their frequency of retinal examinations, method of ophthalmoscopy and collaboration habits may differ from that of the non-participants. Second, practice registration data was recorded for consecutive patients to avoid selection bias, however, the reported patient histories relied on patients' self-report and memory recall. Third, the practice registration may have influenced the way the optometrists performed their routine examination. Finally, we did not observe the optometrists' work and their conclusions were not verified.

\section{Conclusion}

Optometric practice is a low threshold setting for casefinding of ocular pathology and retinal manifestations of systemic disease in the population. At present, the diagnosis of retinopathies in Norwegian optometric practice is unreliable. There are potentials for improving the optometrists' routine examination, their patient management patterns and collaboration routines with medical doctors.

\section{List of abbreviations used}

AMD: Age related macular degeneration; CVD: Cardiovascular disease; GP: General practitioner; HTN: Hypertension; NAO: Norwegian Association of Optometrists.

\section{Competing interests}

The authors declare that they have no financial competing interests.

VS is a member of the Norwegian Optometric Associations' board of continuing education and board of optometric rehabilitation.

\section{Authors' contributions}

VS conceived of the study and participated in its design, acquisitioned and statistically analysed the data and drafted the manuscript. PG participated in the design of the study and interpretation of data, and helped to draft the manuscript. JS participated in the design of the study and helped to draft the manuscript. RB, LSB and JJ participated in the design of the study and critically revised the manuscript. All authors read and approved the final manuscript.

\section{Acknowledgements}

We thank the optometrists participating in the study and Dr. Patricia M. Riddell for helpful comments.

\section{References}

I. Di Stefano A: World optometry: the challenges of leadership for the new millennium. Optometry 2002, 73(6):339-350.

2. Hamakiotes DS, Thal LS: The unification of European optometry: how the profession will change after 1992. J Am Optom Assoc 1991, 62(12):904-913.
3. Buch H, Vinding T, La Cour M, Appleyard M, Jensen GB, Nielsen NV: Prevalence and causes of visual impairment and blindness among $\mathbf{9 9 8 0}$ Scandinavian adults: the Copenhagen City Eye Study. Ophthalmology 2004, I I I(I):53-6I.

4. Williams R, Airey M, Baxter H, Forrester J, Kennedy-Martin T, Girach A: Epidemiology of diabetic retinopathy and macular oedema: a systematic review. Eye 2004, I 8( I 0):963-983.

5. Younis N, Broadbent DM, Harding SP, Vora JR: Prevalence of diabetic eye disease in patients entering a systematic primary care-based eye screening programme. Diabet Med 2002, 19(12): I014-1021.

6. Skrivarhaug T, Fosmark DS, Stene LC, Bangstad HJ, Sandvik L, Hanssen KF, Joner G: Low cumulative incidence of proliferative retinopathy in childhood-onset type I diabetes: a 24-year follow-up study. Diabetologia 2006, 49(I 0):228I-2290.

7. Nordwall M, Bojestig M, Arnqvist HJ, Ludvigsson J: Declining incidence of severe retinopathy and persisting decrease of nephropathy in an unselected population of Type I diabetes-the Linkoping Diabetes Complications Study. Diabetologia 2004, 47(7): $1266-1272$

8. Hovind P, Tarnow L, Rossing K, Rossing P, Eising S, Larsen N, Binder $\mathrm{C}$, Parving $\mathrm{HH}$ : Decreasing incidence of severe diabetic microangiopathy in type I diabetes. Diabetes Care 2003, 26(4): $1258-1264$

9. Henricsson M, Nystrom L, Blohme G, Ostman J, Kullberg C, Svensson M, Scholin A, Arnqvist HJ, Bjork E, Bolinder J, Eriksson JW, Sundkvist $G$ : The incidence of retinopathy 10 years after diagnosis in young adult people with diabetes: results from the nationwide population-based Diabetes Incidence Study in Sweden (DISS). Diabetes Care 2003, 26(2):349-354.

10. Schmid KL, Swann PG, Pedersen C, Schmid LM: The detection of diabetic retinopathy by Australian optometrists. Clin Exp Optom 2002, 85(4):22I-228.

II. Olson JA, Strachan FM, Hipwell JH, Goatman KA, McHardy KC, Forrester JV, Sharp PF: A comparative evaluation of digital imaging, retinal photography and optometrist examination in screening for diabetic retinopathy. Diabet Med 2003 , 20(7):528-534.

12. Hulme SA, Tin UA, Hardy KJ, Joyce PW: Evaluation of a districtwide screening programme for diabetic retinopathy utilizing trained optometrists using slit-lamp and Volk lenses. Diabet Med 2002, 19(9):74I-745.

13. Prasad S, Kamath GG, Jones K, Clearkin LG, Phillips RP: Effectiveness of optometrist screening for diabetic retinopathy using slit-lamp biomicroscopy. Eye 200I, I 5(Pt 5):595-60I.

14. Sundling V, Gulbrandsen P, Bragadottir R, Bakketeig LS, Jervell J, Straand J: Optometric practice in Norway: a cross-sectional nationwide study. Acta Ophthalmol Scand 2007, 85(6):67I-676.

15. Wong TY, Klein R, Klein BE, Tielsch JM, Hubbard L, Nieto FJ: Retinal microvascular abnormalities and their relationship with hypertension, cardiovascular disease, and mortality. Surv Ophthalmol 200I, 46(I):59-80.

16. Pollack AL, Brodie SE: Diagnostic yield of the routine dilated fundus examination. Ophthalmology 1998, 105(2):382-386.

17. Hutchinson A, Mclntosh A, Peters J, O'Keeffe C, Khunti K, Baker R, Booth A: Effectiveness of screening and monitoring tests for diabetic retinopathy--a systematic review. Diabet Med 2000, I7(7):495-506.

18. Claudi T, Cooper JG, Midthjell K, Daae C, Furuseth K, Hanssen KF: NSAMs handlingsprogram for diabetes $i$ allmennpraksis 2005. Kortversjon [NSAMs guidelines for diabetes in general practice 2005. Short version] In Norwegian. Norsk selskap for allmennmedisin, Den norske Lægeforening, Norges Diabetesforbund; 2005.

19. Nguyen TT, Wong TY: Retinal vascular manifestations of metabolic disorders. Trends Endocrinol Metab 2006, I7(7):262-268.

20. Hapnes $\mathrm{R}$, Bergrem $\mathrm{H}$ : Diabetic eye complications in a medium sized municipality in southwest Norway. Acta Ophthalmol Scand 1996, 74(5):497-500.

21. Riise D, Arnestad JE, Saetrom KM: Bør optikere kunne henvise pasienter til øyelege? [Should optometrists be able to refer patients to ophthalmologists?] In Norwegian, summary in English. Tidsskr Nor Laegeforen 2000, I 20( I 8):2 I |3-2 I |4. 


\section{Pre-publication history}

The pre-publication history for this paper can be accessed here:

http://www.biomedcentral.com/1472-6963/8/38/prepub

Publish with Biomed Central and every scientist can read your work free of charge

"BioMed Central will be the most significant development for disseminating the results of biomedical research in our lifetime. " Sir Paul Nurse, Cancer Research UK

Your research papers will be:

- available free of charge to the entire biomedical community

- peer reviewed and published immediately upon acceptance

- cited in PubMed and archived on PubMed Central

- yours - you keep the copyright 